\title{
Design of a micromanipulation system for high temperature operation in an Environmental Scanning Electron Microscope (ESEM)
}

\author{
P Samara-Ratna $^{1}$, H V Atkinson ${ }^{2}$, T Stevenson ${ }^{1}$, S V Hainsworth ${ }^{2}$ and J Sykes ${ }^{1}$ \\ ${ }^{1}$ Space Research Centre, Department of Physics and Astronomy, University of Leicester, \\ University Rd., Leicester, LE1 7RH, UK. \\ ${ }^{2}$ Department of Engineering, University of Leicester, University Rd., Leicester LE1 7RH, UK. \\ E-mail:hva2@le.ac.uk
}

\begin{abstract}
The Environmental Scanning Electron Microscope (ESEM) allows the sample to be imaged under a low pressure atmosphere. The ability to micromanipulate with precision within heated power systems in an ESEM will enable a greater understanding of the behaviour of materials at high temperature. Heating stages for ESEM's are commercially available but none include micromanipulation systems. Creating such a system is fraught with design problems. This is because the piezoelectric transducers, required to generate the precise range of movement within the heated environment, are unable to operate at temperatures exceeding about $90^{\circ} \mathrm{C}$ and require thermal protection. Here we have used a one dimensional probe as a model of a three dimensional manipulator. We have introduced a thermal break and a thermally insulating extension arm to protect the piezoelectric from heat. We have applied finite element analysis to test the design concepts before practical implementation. This ensures that the piezoelectric transducers in the costly practical devices are not placed at risk. The predictions have been validated with subsequent experimental work although there are some discrepancies to resolve. An example of the movement of aluminium alloy grains and copper powder particles using the one-dimensional manipulator are given.
\end{abstract}

\section{Introduction}

An Environmental Scanning Electron Microscope (ESEM), in contrast to a traditional Scanning Electron Microscope which operates under high vacuum, allows a sample to be imaged under a low pressure atmosphere. Common atmospheres used in an ESEM include water vapour, argon or nitrogen [1]. An electron beam ionises the gas to give positive ions and these, in turn, reduce the charge build-up on the material being sampled, which would otherwise charge negatively due to bombardment with electrons. The ionised gas also acts to amplify the image signal when secondary electrons are used to image the surface. The ESEM can be used with a heating stage where the sample is placed in a small ceramic crucible located above a heater. Above $600^{\circ} \mathrm{C}$, a heat shield, with a small hole to allow imaging, is placed above the ceramic crucible to protect the detector from heating effects. The Gaseous Secondary Electron Detector (GSED) is situated directly above the sample, around the pole piece, and is used to acquire images when the heating stage is in use; other detectors are sensitive to the light emitted by hot samples. The ESEM is, thus, a powerful tool for observing the behaviour of materials at high temperatures. Heating stages for the ESEM are available commercially but there is no such system that would allow the micromanipulation of materials whilst at these high temperatures. This would be valuable, for example, for obtaining detailed micromechanical information on microstructure evolution during sintering, including under applied stress [2]. Micromanipulation systems are well established for use under ambient conditions. The difficulty at high temperatures is that the piezoelectric transducers, used to generate the precise range of movement, begin to permanently degrade by depolarisation above a certain temperature. The manufacturers of the devices we are using recommend not operating above about $90^{\circ} \mathrm{C}$. There is, therefore, an engineering design challenge in establishing a system for protecting the piezoelectric crystals from the heat. This challenge is increased by the restrictions introduced by operating within the space inside the ESEM chamber, in particular the space between the heating stage, the heat shield and the GSED. The aim here was to use finite element analysis to predict the heat flows for design concepts so as to ensure acceptable conditions for 
the piezoelectric device during operation. The predictions were then validated through experiment. The system established is the first high temperature micromanipulation system in an ESEM. It offers the potential not only for experiments which involve moving particles or material at high temperature, but also for microfabrication at high temperature in an ESEM.

\section{The Heating Stage and the Design Concept}

The ESEM used in this work is a Philips XL30 ESEM FEG [3] with a heating stage supplied by FEI [3] (figure 1). The heating stage heats the alumina crucible (diameter $5 \mathrm{~mm}$ ) containing the sample to temperatures between 20 and $1000^{\circ} \mathrm{C}$. The heat is generated by a wire coil located beneath the crucible. The heater wire is surrounded with a ceramic adhesive and potted into an alumina holder. The alumina is surrounded by an insulating zirconia based ceramic called Zircar ZYZ-3 [4]. This is separated into two separate sections to allow the alumina holder to be installed and is encased in a water cooled aluminium housing. A stainless steel heat shield is located above the crucible and provides thermal protection for the GSED of the ESEM. During imaging, the GSED is very close to the heat shield. A small hole in the heat shield allows the centre of the crucible to be viewed. The heating is controlled by a dedicated controller, with an LCD display, which allows the setting of target temperature, temperature ramp and cooling rates. The temperature of the crucible is measured using a thermocouple located directly beneath the heating coil. There may be some discrepancy between the displayed temperature values and the actual value because of the separation between the thermocouple and the crucible. The manufacturer states that final calibration is performed with the heating stage installed inside the ESEM and the temperature reading must fall within $\pm 20^{\circ} \mathrm{C}$ of the calibration temperature (at $760^{\circ} \mathrm{C}$ ) before the stage is accepted to shipment [3]. Calibration is achieved with the use of calibration paints which visibly change at a specified temperature. The position of the thermocouple is adjusted until the composition of the paint changes within the required temperature range.

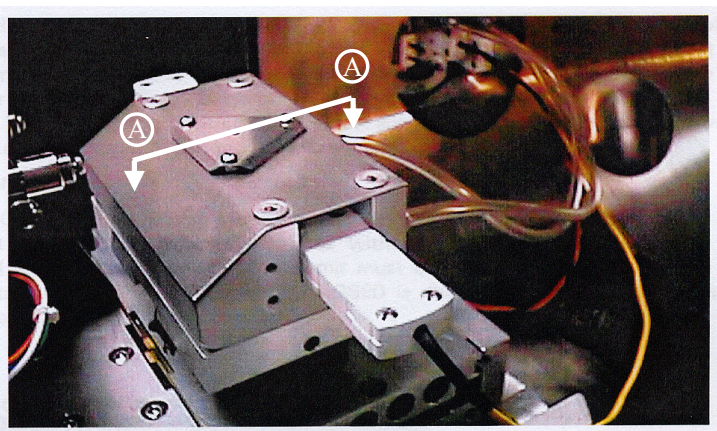

a.) Heating Stage Installed Inside ESEM
1 - Stainless Steel Heat Shield

4 - Alumina Holder

7 - Thermocouple

10 - Water Pipes

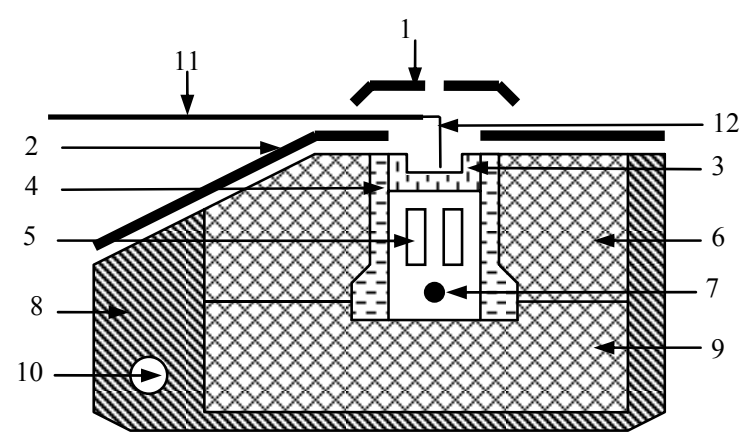

b.) Section A-A

3 - Alumina Crucible

6 - Upper Zircar Block

9 - Lower Zircar Block

12 - Probe Tip

Figure 1. ESEM Heating Stage (a) Heating stage installed in the ESEM (b) cross-section through the stage showing component parts (courtesy of FEI).

For the work reported here, the design concept was initially based on a one-dimensional micromanipulator available from PiezoMotor [5]. This provides movement in one axis in steps of $\sim 5$ microns. The use of a onedimensional manipulator allowed ideas to be tested with a relatively inexpensive piece of equipment, as opposed to using three-dimensional manipulators available on the market. Once 1-D manipulation has been proven the principle will be extended to 3-D manipulation. To protect the piezoelectric device from heat a probe extension arm made of an insulating material (in this case, a hollow alumina tube) was introduced. The manipulator was mounted to one side of the heating stage within an aluminium frame (figure 2). The 1-D probe 
(11 in Figure 2 and 4 in Figure 3) was not mounted on the heating stage because it needs to move independently from the three axes of movement of the stage itself. A copper block (3 in Figure 3) was introduced between the alumina arm of the piezoelectric motor and the probe arm to create a thermal break. It also acts as a heat sink but the material was not chosen to optimise this (otherwise a higher emissivity would have been sought). Minimising heat transfer from the copper block to the temperature sensitive piezoelectric motor was achieved by connecting the square-section piece of alumina on the piezoelectric motor into a drilled cylindrical hole in the copper block such that a friction fit is formed as shown in Figure 2.

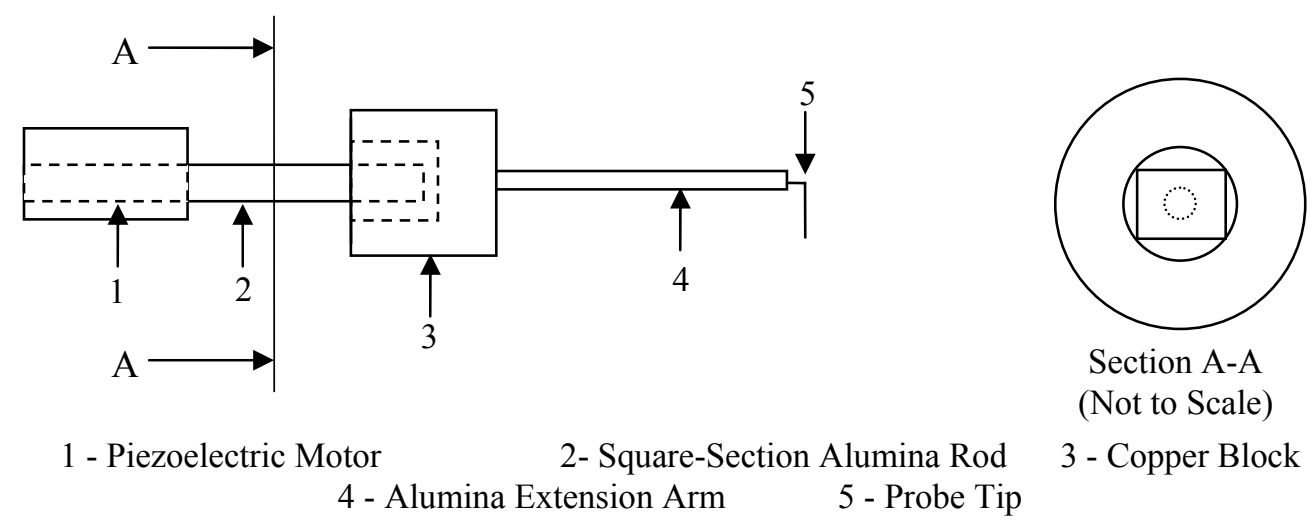

Figure 2 Manipulator Probe Design (not to scale)

In this arrangement conduction of heat to the piezoelectric motor was only possible through the edges of the alumina and the smooth, shiny surface of the copper block limits the radiative heat transfer. The probe arm was sufficiently small to fit through the narrow gap of approximately $2 \mathrm{~mm}$ created between the heat shield and the stainless steel cover of the heating stage. At the end of the probe, a tungsten tip was attached which juts down into the ceramic crucible and, hence, into the sample to provide manipulation (see figure 3). The axis of movement was parallel with the probe arm. A vertical height adjuster was required to ensure that the manipulator arm was at precisely the right level to fit under the heat shield without lifting it. This was part of the aluminium mounting frame. A temperature sensor was attached to the copper block as a precaution to ensure that the piezoelectric motor was not damaged.

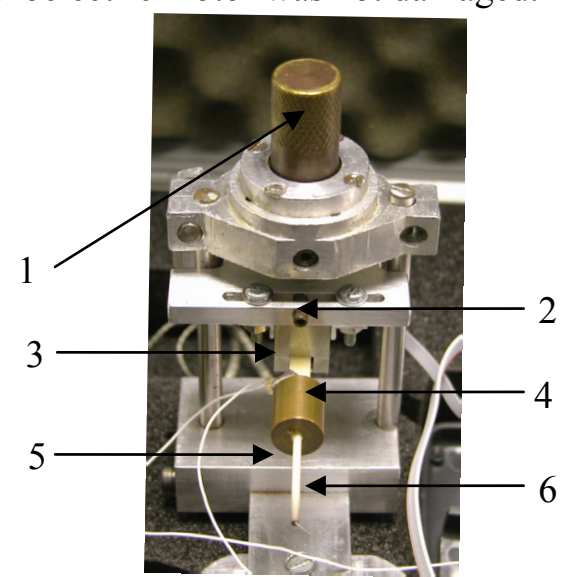

a.)

1 - Vertical Height Adjuster

3 - Temperature Sensor

5 - Alumina Probe

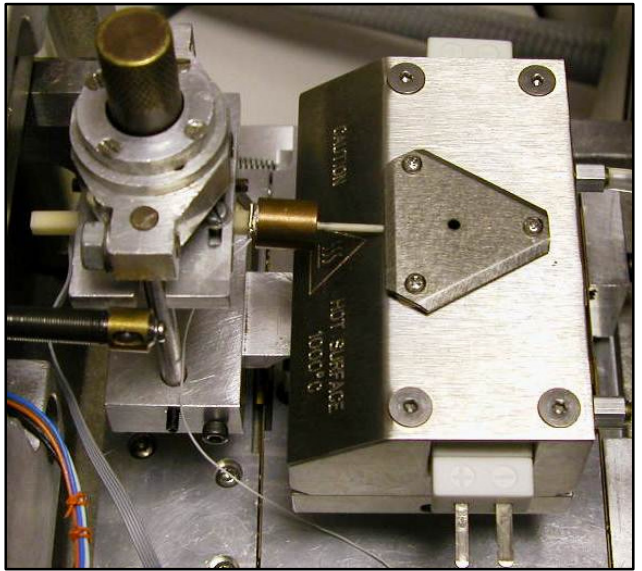

b.)

2 - Piezoelectric Manipulator

4 - Copper Block

6 - Tungsten Tip

Figure 3. One-dimensional manipulator a.) Manipulator and Mounting Frame b.) Manipulator installed in ESEM 


\section{Construction of Finite Element Model}

A Computed Aided Design (CAD) model of the heating stage was created using dimensions provided by the heating stage manufacturers, FEI [3]. The model was appropriately meshed to create the Finite Element (F.E.) model shown in Figure 4. All modelling was performed using the I-Deas engineering software [6] in conjunction with MAYA's TMG solver [7]. Components of the heating stage were modelled as accurately as possible and included modelling of the heater wire coils and cooling fluid. The high level of detail was introduced as initially it was not clear which features of the heating stage dominated performance. The final model contained 10281 nodes and 22216 elements. Mesh density was increased in the locality of the heat source to improve results. Other components outside the area of prime interest were meshed with the largest possible mesh to reduce computation time.

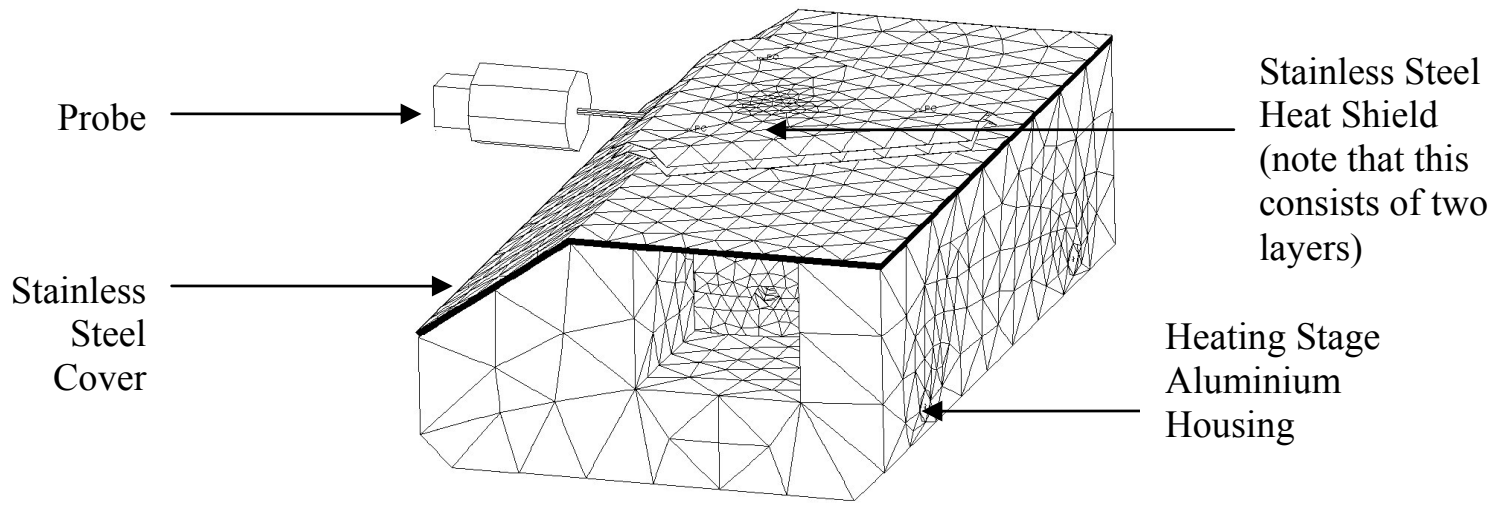

Figure 4. F.E. Model of Heating Stage and Manipulator Probe

The ESEM operates at a pressure of 2 torr or lower. Taking into account the pumping speed and ESEM chamber size the flow conditions are considered to be transitional and molecule mean free path is close to the chamber diameter [8]. In these conditions the primary modes of heat transfer for the heating stage are by conduction and radiation. Therefore convection is considered negligible and not included in the analysis.

Conductance modelling was performed using the Finite Element Centre of Gravity (CG) method. This method establishes a calculation point in the element's centre of gravity as well as at each boundary [9]. Conductance is established between the boundary points using an algorithm which constrains linear element temperature functions to satisfy the governing partial differentiation equation. The calculation point at the centre of gravity is used to distribute heat transfer to the boundary nodes in the element. The element temperature is computed assuming a piecewise linear temperature distribution in the element. The solver evaluates temperature at each calculation point and once the matrix is solved, temperatures are interpolated to the mesh nodes. The CG method is chosen in preference to the Element Centre method as it generates high accuracy results, facilitates modelling of temperature dependant properties and has little sensitivity to element distortion. However, this led to longer solve times.

Each component of the heating stage is filled with linear tetrahedron solid elements and covered in a shell of null thickness. The conductance is achieved by defining thermal coupling between null shell layers. This method enables heat transfer to occur between bodies without the need for a physical coupling. For analysis, conductance paths between materials in close proximity are assumed perfect. This is due to the difficulty in determining the degree of contact between parts. This assumption may be the cause of errors as without contact only radiative heat transfer occurs. However, it is extremely difficult to determine an appropriate conductance value as many variables are involved. The heating stage was disassembled and it was found there was nearfriction fit between parts and this gave confidence that a perfect contact assumption could be applied. Perfect contact is simulated in the model by specifying very high conductance values in the thermal coupling between parts.

Linking different parts by thermal couplings must be performed carefully to avoid production of thermal "shortcircuits". If thermal couplings are applied incorrectly the model can produce unnatural conductance paths which 
produce unrealistic results. Validation of the model was achieved by applying thermal boundaries around groups of parts with thermal couplings and comparing the results to hand calculations using Fourier's conductance law. This method of validation allows gross errors in the model to be identified without the need to generate complex validation calculations. However, this method does not allow small errors to be identified as agreement between hand calculations and the analytical model is often not close. In most cases, the user had to determine whether the results were sufficiently close for acceptability, based on the area of the model being considered. For example, the walls of the alumina holder (labelled as 4 in Figure 1 section b) surrounding were checked by applying a $1000 \mathrm{~W}$ heat load on the inside surface while the external surface is held at $250^{\circ} \mathrm{C}$. Fouriers law determines that the interior wall temperature should be $1067^{\circ} \mathrm{C}$ and the model predicts $932^{\circ} \mathrm{C}$, thereby giving a $12.7 \%$ error. This is sufficiently close given that the calculation does not account for the thicker bottom section of the alumina holder. The thicker bottom section will cause the calculated result to be higher than the F.E. model. This gives further confidence that this region of the model operates correctly.

Distorted elements can result in the generation of negative conductances within elements. The mesh was checked for angles larger than $135^{\circ}$ as these can cause potential conductance problems [10]. Where these elements existed, the mesh density was redefined until as many large angle elements as possible were removed from the analysis. Removal of all large angles was not possible and the solver was required to perform some modifications to conductances within elements. Steps were taken to ensure that conduction modification was minimised and ultimately only $0.44 \%$ of the elements were affected. The modified elements were not constrained to a single part and were distributed throughout the model. Therefore the conduction modification was considered sufficiently small to be ignored and results would be dominated by the correctly operating elements.

I-Deas TMG Thermal Analysis (TMG) allows the thermal couplings between elements to occur either between elements that overlap across the thermal coupling or between all elements. In all cases, it was appropriate for heat transfer to occur between overlapping elements. Generally it was discovered that connecting thermal couplings using all available elements resulted in an unnatural dispersion of heat through the system as unrealistic thermal paths were generated.

Radiation is modelled using the standard radiation solver within the TMG package. Heat transfer between internal components of the heating stage is dominated by conduction as contact is assumed perfect. Therefore, radiation modelling was only applied to surfaces exposed to ambient conditions and was only performed between the thin shells surrounding solid parts and beam elements. Solid elements are ignored and reliance is placed on the null shells surrounding the parts to generate radiative heat transfer. To absorb energy from the system a "space enclosure" is created around the stage. The space enclosure creates one large cube made of six or more elements that enclose the model and local space around it [10]. The calculation of radiative heat transfer is based on view factors between pairs of elements. Objects with direct line of sight have their view factors calculated first. The remaining elements have shadowing checks performed to determine the proportion of radiative heat transfer available based on unobstructed area [10].

\section{Material Properties}

The thermal properties of materials were carefully chosen and defined to vary with temperature to produce realistic results. Most properties were extracted from standard text books and from manufacturer data sheets. However, emissivity and absorptivity are dependant upon surface finish and environmental conditions and these properties were varied to see what effect the changes had on the overall results and used as a means of fine tuning the model. The final material properties used in the model are given in table 1 . The sensitivity of the F.E. model to the values is evaluated by changing, in turn, all thermal conductivity values by $50 \%$ from the optimal value and determining the percentage change of temperature at the centre of the crucible. The dominance of the thermal conductance of the Zircar is clear as the sensitivity to its thermal conductivity is approximately 22 times greater than that of the next most influential material alumina. The Table shows conductance values up to $3000^{\circ} \mathrm{C}$ and this is above the maximum operable temperature for many materials. However, the values were used as an upper limit in calculations and in analysis temperatures were never developed in this region. 


\begin{tabular}{|c|c|c|c|c|c|c|c|c|}
\hline 总 & $\stackrel{t}{0}$ & 3 & $\underset{\substack{J \\
\infty \\
0 \\
0}}{\Xi}$ & $\overleftrightarrow{z}$ & $\begin{array}{l}\bar{\sigma} \\
\stackrel{\alpha}{\alpha} \\
0\end{array}$ & $\overleftrightarrow{\mathbf{z}}$ & $\begin{array}{l}\frac{5}{2} \\
\stackrel{0}{0} \\
0\end{array}$ & $\stackrel{\infty}{0}$ \\
\hline & $\stackrel{\stackrel{a}{\circ}}{\circ}$ & & $\stackrel{0}{=}$ & & & $\stackrel{\mathscr{o}}{\stackrel{\leftrightarrow}{a}}$ & $\stackrel{8}{q}$ & g \\
\hline 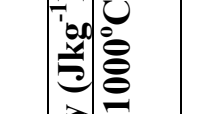 & $\stackrel{\infty}{\stackrel{\rho}{a}}$ & & $\bar{\Xi} \Xi$ & & & $\stackrel{\mathscr{o}}{\stackrel{\leftrightarrow}{a}}$ & $\stackrel{8}{q} \Xi$ & $\stackrel{g}{ \pm} \Xi$ \\
\hline | & 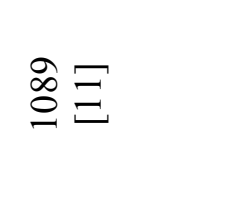 & $\begin{array}{l}\bar{m} \\
\dot{0} \\
\tilde{n} \\
i\end{array}$ & $\bar{\Xi} \Xi$ & $\stackrel{\circ}{F}$ & \begin{tabular}{l}
$n$ \\
0 \\
8 \\
\hdashline
\end{tabular} & $\stackrel{\circ}{\stackrel{\circ}{g}}$ & $\stackrel{\partial}{\vec{\sigma}} \Xi$ & q \\
\hline 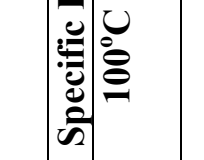 & $\vdots \Xi$ & & $\hat{n} \Xi$ & & & à & 官 $\Xi$ & \\
\hline : & $\stackrel{\infty}{\curvearrowright} \Xi$ & & $\stackrel{\infty}{\infty} \Xi$ & & & $\stackrel{\infty}{\curvearrowright}$ & 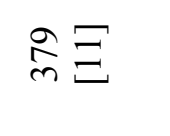 & \\
\hline 雚 & in & त् & & 8 & & in & & \\
\hline 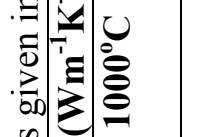 & $\Xi_{0}$ & $\stackrel{m}{0}$ & & 8 & & 6 & & \\
\hline 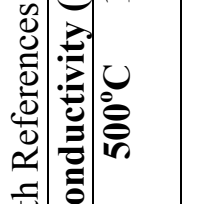 & $\underset{\Xi}{\Xi}$ & $\stackrel{\circ}{\stackrel{\circ}{0}}$ & 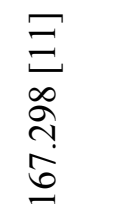 & $\Xi_{0}$ & $\begin{array}{l}\hat{\tilde{n}} \\
\underline{n} \\
\underline{n}\end{array}$ & $r$ & $\underset{\Xi}{\Xi}$ & $\begin{array}{l}\underset{\Xi}{\Xi} \\
\stackrel{0}{0}\end{array}$ \\
\hline 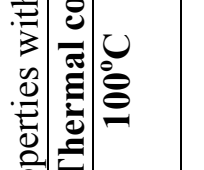 & $\begin{array}{l}\Xi \\
\Xi\end{array}$ & $\stackrel{0}{0}$ & & $\underset{\Xi}{\Xi}$ & & $=$ & & \\
\hline 豙 & $\underset{\substack{\infty \\
m}}{\Xi}$ & : & & 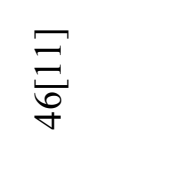 & & $\stackrel{\infty}{m}$ & & \\
\hline 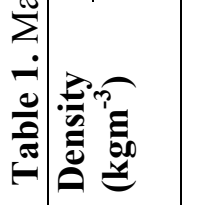 & 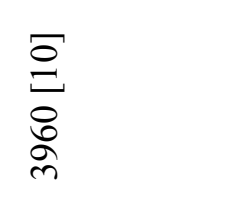 & 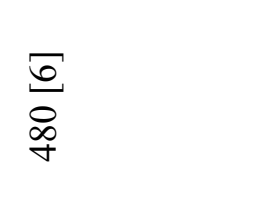 & 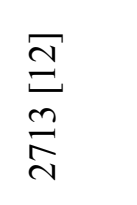 & 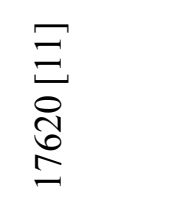 & $\frac{n}{0} \Xi$ & 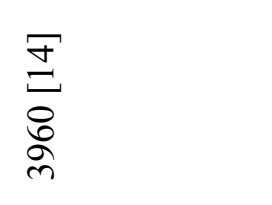 & $\begin{array}{l}\Xi \\
\substack{0 \\
\infty \\
\infty}\end{array}$ & $\begin{array}{l}\Xi \\
\Xi \\
\infty \\
\infty \\
\infty\end{array}$ \\
\hline 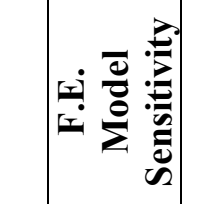 & d̊ & $\underset{\infty}{\stackrel{0}{\grave{~}}}$ & 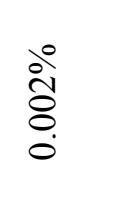 & 递 & 总 & 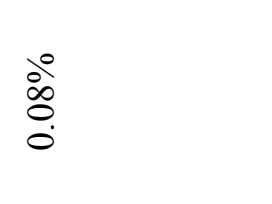 & $\widehat{\overleftarrow{z}}$ & $\overleftrightarrow{z}$ \\
\hline 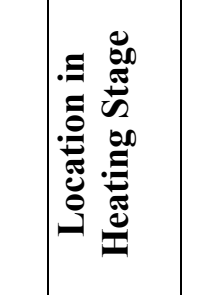 & 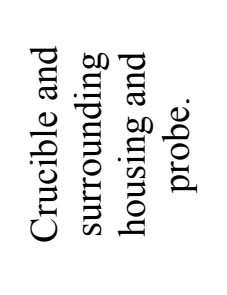 & 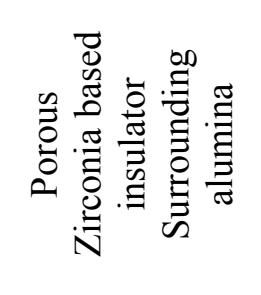 & 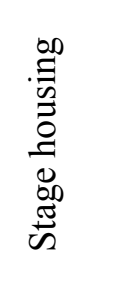 & 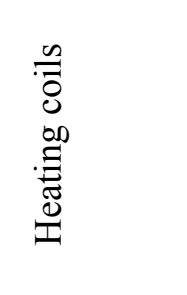 & 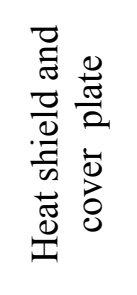 & 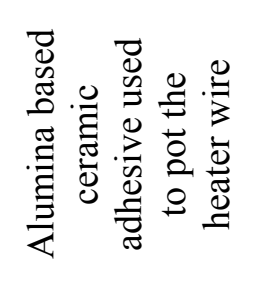 & 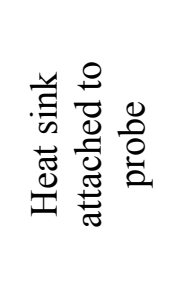 & $\begin{array}{l}\because \\
0 \\
0 \\
0 \\
0\end{array}$ \\
\hline 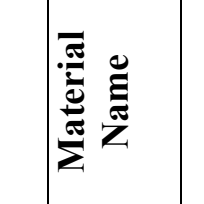 & 㳯 & 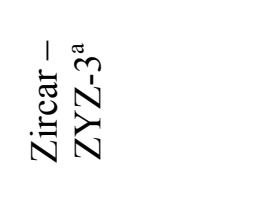 & 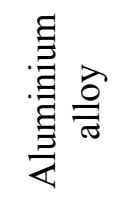 & 仓。言害言 & 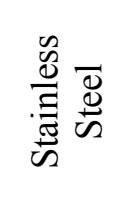 & 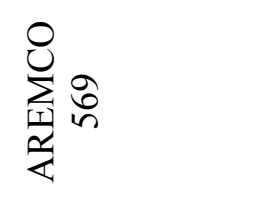 & $\begin{array}{l}\overline{\tilde{\omega}} \\
\overline{0} \\
\overline{0}\end{array}$ & 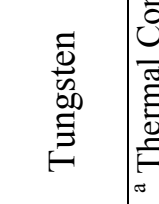 \\
\hline
\end{tabular}




\section{Results from the F. E. Model for the Heating Stage}

Heat is generated in the model by applying a transient heat load to the wire coils of the heater. The heat load is derived from experiments in which voltage and current measurements were taken during the heating cycles as shown in Figure 5.

\begin{tabular}{cc}
\hline $\begin{array}{c}\text { Temperature } \\
\left({ }^{\circ} \mathbf{C}\right)\end{array}$ & $\begin{array}{c}\text { Ramp Rate } \\
\left({ }^{\circ} \mathbf{C} / \mathbf{m i n}\right)\end{array}$ \\
\hline 400 & 40 \\
400 & $\begin{array}{c}\text { Hold for } 5 \\
\text { minutes }\end{array}$ \\
30 & 20 \\
0 & 1
\end{tabular}

a.) $400^{\circ} \mathrm{C}$ Maximum Set-Point

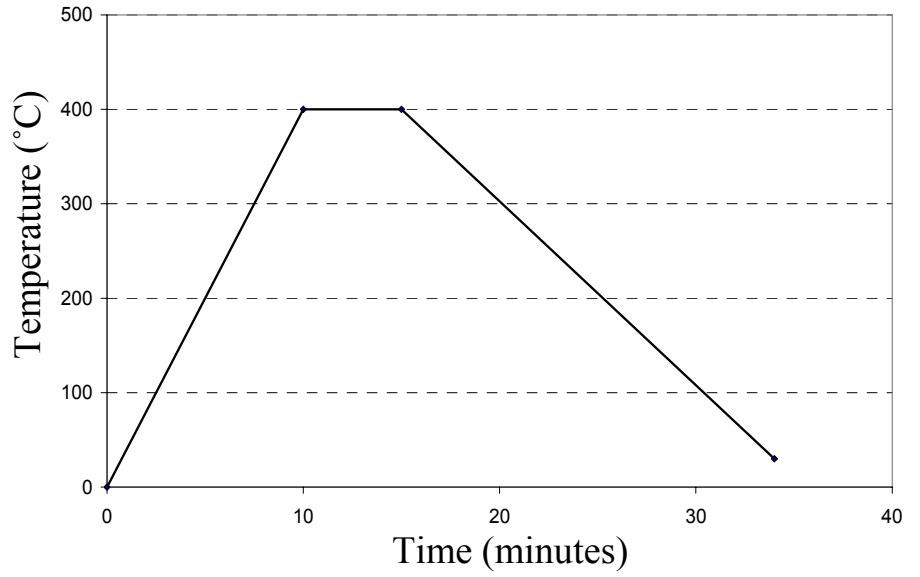

\begin{tabular}{cc}
\hline $\begin{array}{c}\text { Temperature } \\
\left({ }^{\circ} \mathbf{C}\right)\end{array}$ & $\begin{array}{c}\text { Ramp Rate } \\
\left({ }^{\circ} \mathbf{C} / \mathbf{m i n}\right)\end{array}$ \\
\hline 500 & 20 \\
580 & 5 \\
580 & $\begin{array}{c}\text { Hold for } 3 \\
\text { minutes }\end{array}$ \\
650 & 5 \\
30 & 20 \\
0 & 1
\end{tabular}

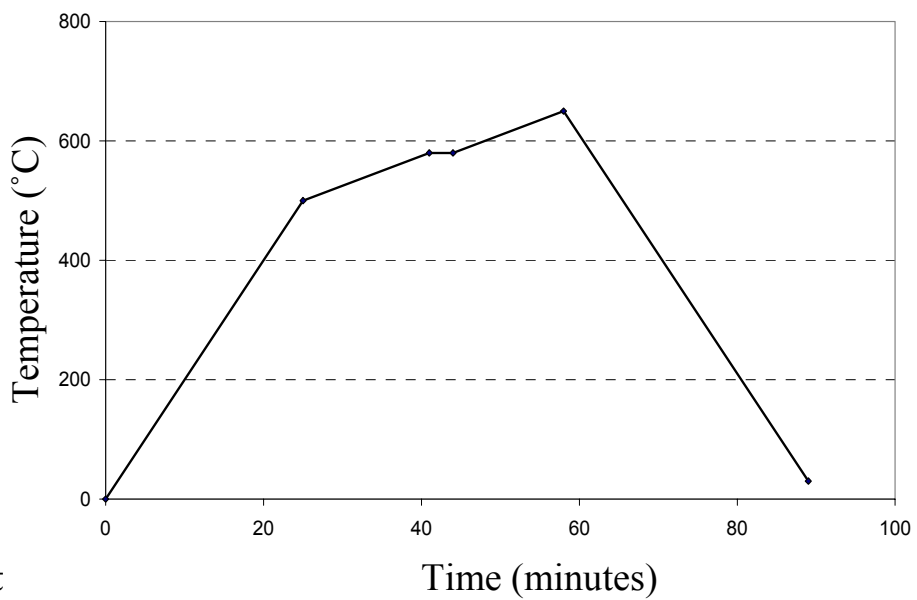

b.) $650^{\circ} \mathrm{C}$ Maximum Set-Point

\begin{tabular}{cc}
\hline $\begin{array}{c}\text { Temperature } \\
\left({ }^{\circ} \mathbf{C}\right)\end{array}$ & $\begin{array}{c}\text { Ramp Rate } \\
\left({ }^{\circ} \mathbf{C} / \mathbf{m i n}\right)\end{array}$ \\
\hline 500 & 10 \\
900 & 5 \\
900 & $\begin{array}{c}\text { Hold for } 10 \\
\text { minutes }\end{array}$ \\
30 & 20 \\
0 & 1 \\
\hline
\end{tabular}

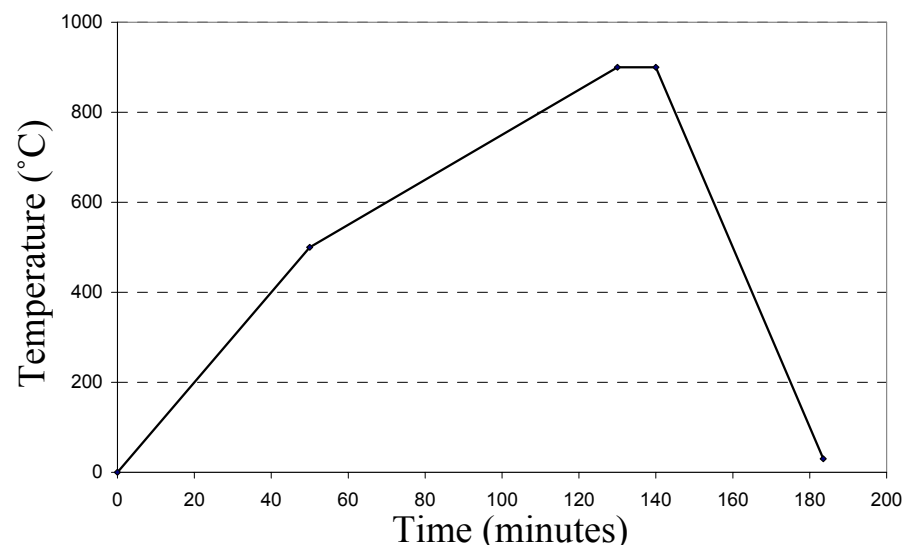

\section{c.) $900^{\circ} \mathrm{C}$ Maximum Set-Point}

Figure 5. Temperature and Ramp Rate for Experiments in which Voltage and Current were Measured for Use in Power Calculations 
In a full analysis on a standard Mobile Pentium Laptop computation time for a full transient analysis takes approximately 1 hour.

The F.E. model shows that performance of the heating stage is dominated by the thermal conductivity of the Zircar surrounding the alumina crucible core and by the emissivity of the alumina crucible. The Zircar block surrounds the heater and its very low thermal conductivity enables heat to be stored within the crucible. The main thermal path for heat to leave the stage is by radiation through the crucible surface. As the emissivity of alumina is hard to determine, the property was used as a means of providing fine tuning in order for results to correlate with experimental data.

In the heating stage, the temperature of the crucible is measured remotely through a thermocouple mounted underneath the heater. In the finite element model, a node was located at the same position as the thermocouple to create a measurement location to predict thermocouple temperatures. A comparison between the temperatures at the crucible surface to the thermocouple during transient analysis is shown in Figure 6. The result shows that, in at least analytical terms, the thermocouple output and the temperature of the crucible should be very similar across the operating temperature range.

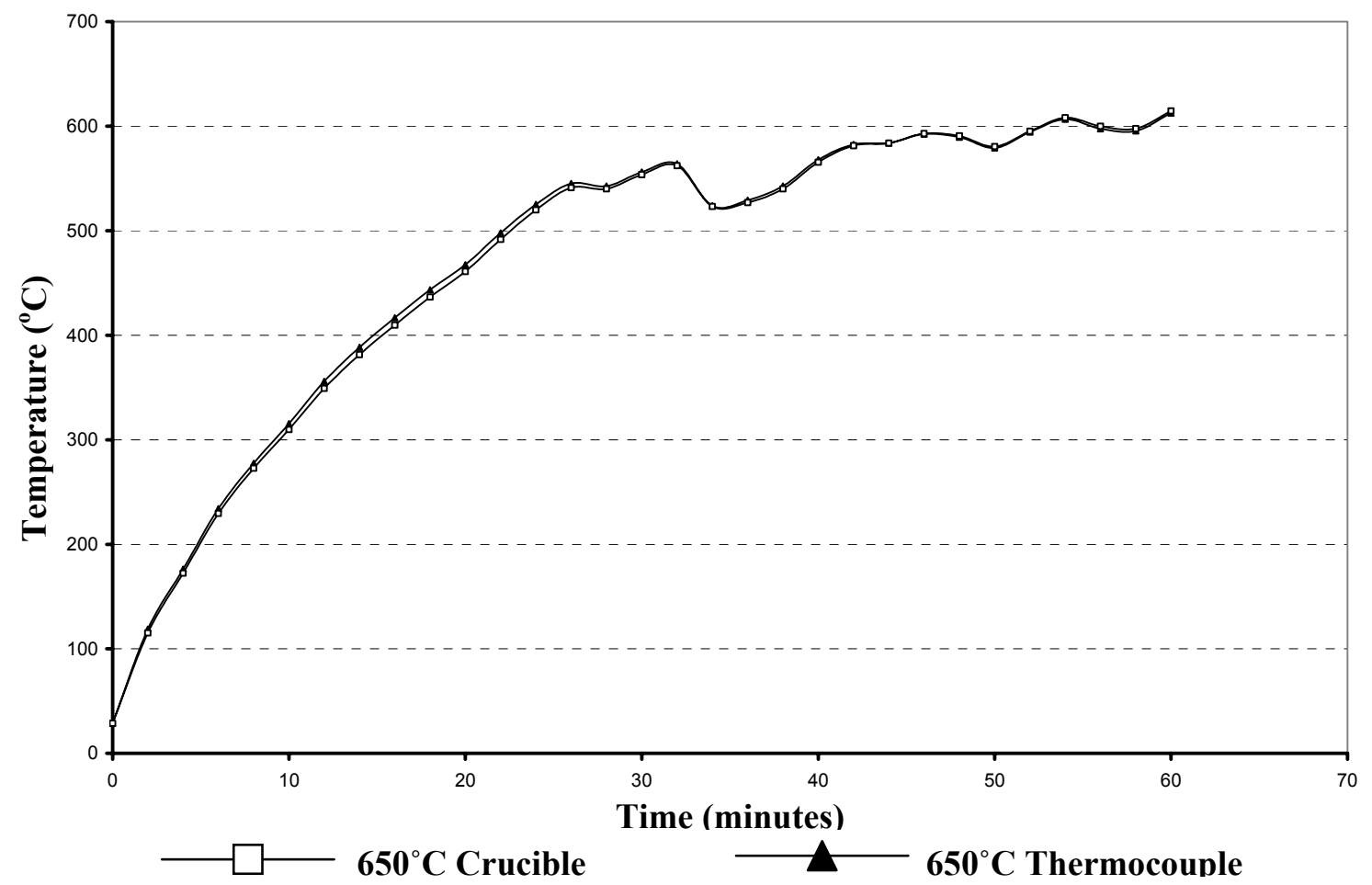

Figure 6. Comparison between Thermocouple and Crucible Temperatures

A typical illustrative result showing heat distribution through a central cross-section of the heating stage for a given power is shown in figure 7. This is for the maximum temperature during a $900^{\circ} \mathrm{C}$ set-point experiment (see figure 5) after the 10 minute hold. 


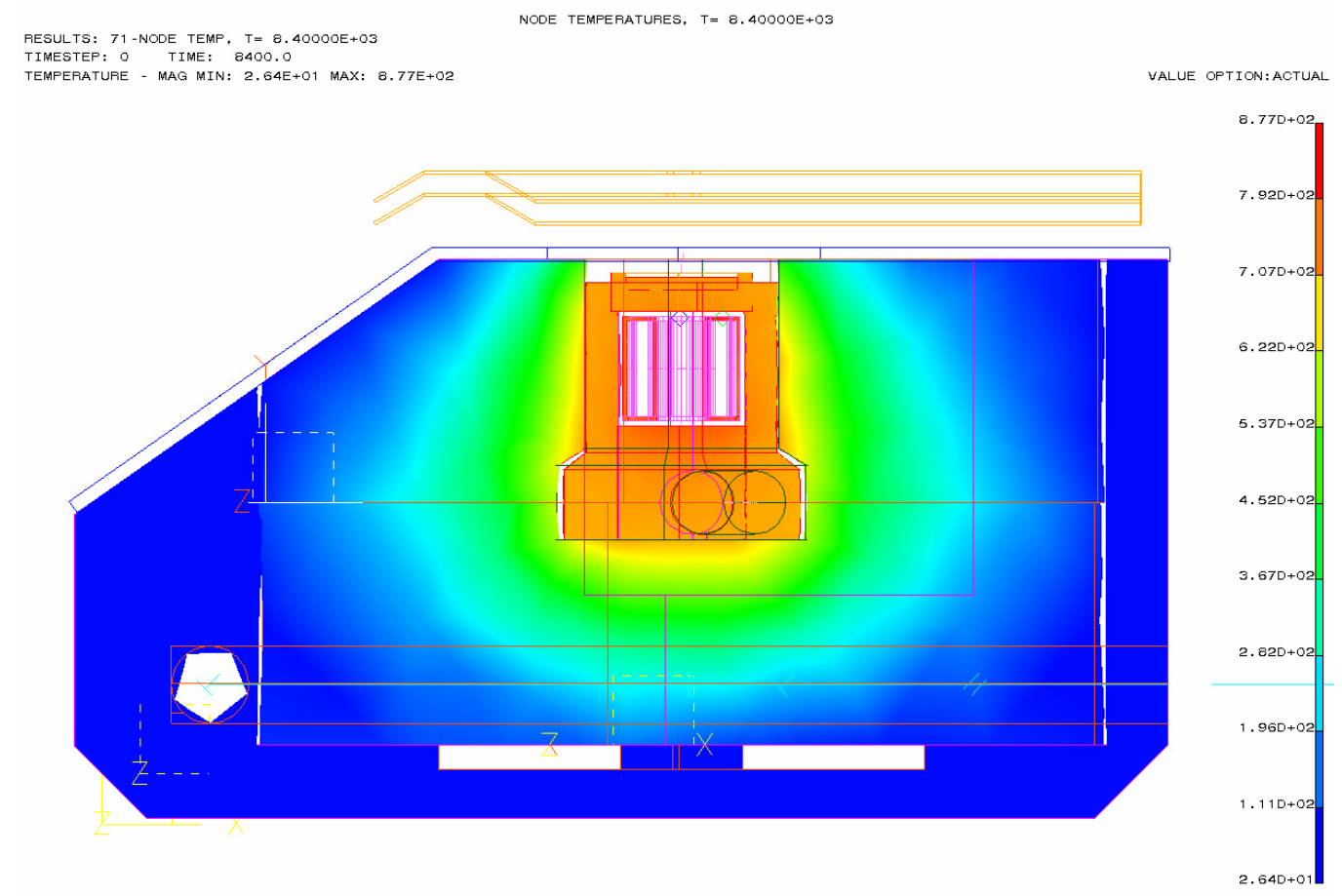

Figure 7.Temperature distribution through heating stage after 10 minutes hold for a Set-Point of $900^{\circ} \mathrm{C}$ (see Figure 5c)

\section{F.E. Modelling of the Micromanipulator}

The 1-D manipulator actuates a probe which has a tungsten needle tip to provide manipulation of the sample. The maximum operating temperature of the manipulator is about $90^{\circ} \mathrm{C}$ and to provide thermal protection the probe is required to limit heat transfer to the piezoelectric motors. The F.E. model was used to design the probe and prove its feasibility before implementation in the heating stage. The probe is modelled using beam elements of appropriate section sizes. In addition, an aluminium alloy disc was modelled inside the crucible to represent the sample. The probe is modelled assuming a worst-case scenario, whereby the probe tip is submerged into the sample and is in perfect contact with the crucible. This generates the maximum possible heat transfer into the probe. The main section of the probe was constructed using alumina ceramic thin-walled tube due to its structural stability over a large temperature range, low thermal conductivity and high melting point. In reality, zirconia would be a better material choice but it was not possible to procure an appropriate section size. The F.E. model was used to simulate a single length of alumina acting as the extension arm. As with the modelling of the heating stage, perfect conduction is assumed between the elements. This is achieved by sharing nodes between beam elements and does not require the specification of thermal couplings. The results for a $650^{\circ} \mathrm{C}$ set-point temperature showed that the temperature of the piezoelectric was $121^{\circ} \mathrm{C}$ and would be damaged. To improve the thermal protection, a cylindrical copper block and larger square section of alumina was incorporated as indicated in figure 2.

The cylindrical copper block has holes drilled into either end to accommodate both sections of alumina and coupling is assumed perfect. However, the square section alumina is attached using a friction fit connection at each corner. This minimises conduction and heat transfer is dominated by radiation. The connection is modelled by creating a small gap of $0.1 \mathrm{~mm}$ between the copper block and the alumina through which a near-zero conductance is specified. The parts are sufficiently close that radiative heat transfer is representative. The F.E. model analysis showed that with this arrangement the piezoelectric would remain within safe operating temperatures across the operating range of the heating stage. A comparison between the F.E model predicted temperatures 
and temperatures measured during experiment (for $650^{\circ} \mathrm{C}$ set-point) is shown in Figure 8 . The results show reasonable agreement and validate the analytical approach. The figure also shows the temperature distribution across the probe with a single length of alumina.
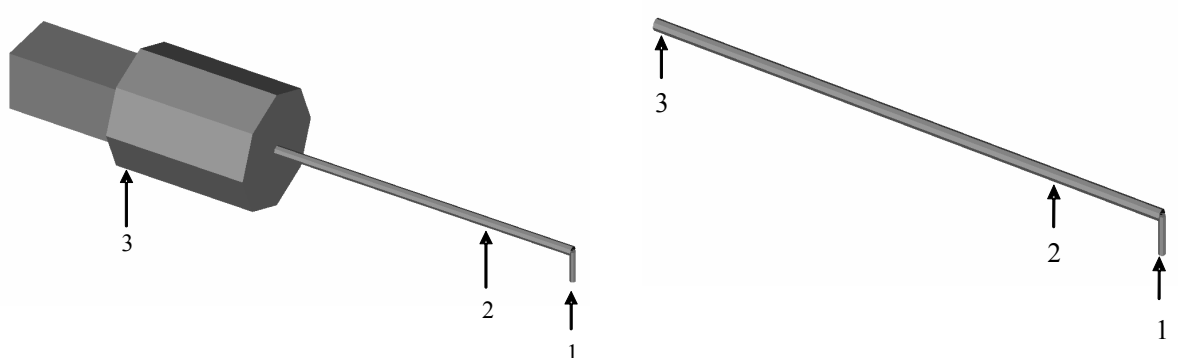

\begin{tabular}{|c|c|c|c|}
\hline \multirow[t]{2}{*}{ Location } & \multicolumn{2}{|c|}{$\begin{array}{c}\text { Probe With Copper Block } \\
\text { Arrangement }\end{array}$} & \multirow{2}{*}{$\begin{array}{c}\text { Probe without Copper Block } \\
\text { F.E. Model Prediction } \\
\left({ }^{\circ} \mathrm{C}\right)\end{array}$} \\
\hline & $\begin{array}{c}\text { Experiment Temp } \\
\left({ }^{\circ} \mathrm{C}\right)\end{array}$ & $\begin{array}{l}\text { F.E. Temp. } \\
\quad\left({ }^{\circ} \mathrm{C}\right)\end{array}$ & \\
\hline $1-$ Probe Tip & 603 & 605.4 & 605.3 \\
\hline $\begin{array}{c}2-25 \% \text { along } \\
\text { Alumina Rod from } \\
\text { tip }\end{array}$ & 123.4 & 119.2 & 173.9 \\
\hline $\begin{array}{l}3 \text { - Copper Block } \\
\text { End }\end{array}$ & 51.3 & 52.4 & 121 \\
\hline
\end{tabular}

Figure 8. Comparison of F.E. and Experimental Results for Manipulator Probe Design for a $650^{\circ} \mathrm{C}$ Set-Point Temperature after 1 hour of heating

Discrepancies between the experimental values and the F.E. model are expected due to limitations in both methods. The F.E. model assumes perfect conditions which are not always represented in the heating stage experiments. Even when using the calibrated model continual changes in the environment and heating stage performance are not accounted for and can result in errors when using the model to predict temperatures for different heat loads. In addition during experiments up to 6 measurements were taken by hand using various digital meters at a single interval. These measurements took up to 20 seconds to record and introduced errors as values are continuously changing. The introduction of measuring equipment (e.g. thermocouples) adds additional sources of heat loss which result in the stage behaving differently to when a sample is being heated. The extents of these errors are difficult to quantify due to their variability. It is reasonable to assume that the differences in experimental temperatures and F.E. model temperatures can be largely accounted for by these errors. However, as a safety precaution to any unexpected changes in performance which could result in the damage of the piezoelectric motor a temperature sensor was added onto the copper block connected to the 1-D manipulator probe.

In addition to protecting the piezoelectric transducers, the probe must not act as a heat sink and remove significant quantities of heat from the crucible. This could lead to localised cold regions being created in the sample. The F.E. model was used to check this and figure 9 shows the temperature distribution across the sample when the probe is attached. The result shows that no localised cold regions are formed in the sample. 


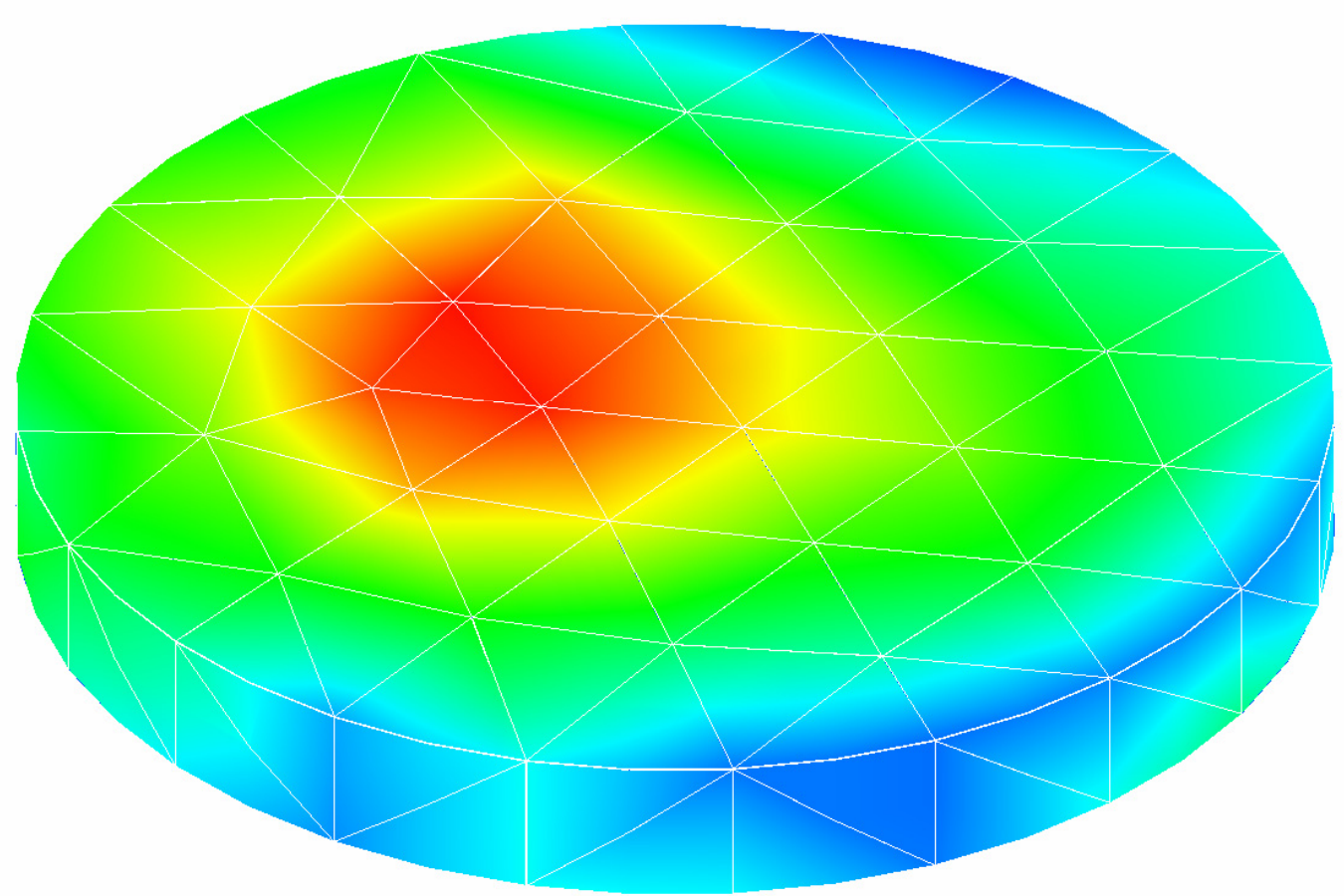

Figure 9. Temperature distribution across the sample in the crucible for a $650^{\circ} \mathrm{C}$ Set-Point Temperature

The temperature distribution is shown extremely clearly across the crucible surface. The coils of the heating wires are closest at the centre and therefore peak temperatures in the crucible are developed in this region. However, the cooling water runs along one side of the heating stage and this creates a cooler region along one side. The effect on the sample is shifting of the hot region slightly away from the centre and towards the hotter side of the heating stage. It is important to note that the maximum temperature variation across the crucible is only $3^{\circ} \mathrm{C}$ indicating that most experiments can be conducted in any region of the crucible.

\section{Experimental Validation}

Experiments were conducted whereby thermocouples were bonded to key points of the heating stage. These bonding locations included the crucible surface and along the 1-D probe. In these experiments the 1-D manipulator probe tungsten tip was used to pin the thermocouple to the crucible surface, which was filled with AREMCO 569 alumina based ceramic adhesive [12] to ensure good thermal conduction. It was found that without bonding the thermocouple and the probe tip to the crucible surface incorrect temperatures were measured as the thermocouple tended to lift from the crucible surface. In this case, the thermocouple would only measure radiative heat which is significantly lower than the actual surface temperature. A comparison of F.E. and temperatures recorded during experiments is shown in Figures 10. Each set of result uses different ramp inputs and peak temperatures. The results show reasonable correlation between the F.E and experimental data. 
For the $650^{\circ} \mathrm{C}$ set-point experiment there is approximately $45^{\circ} \mathrm{C}$ between the experimental result and the prediction at the end of the run. This maybe associated with the errors for thermocouple measurement discussed in Section 6.

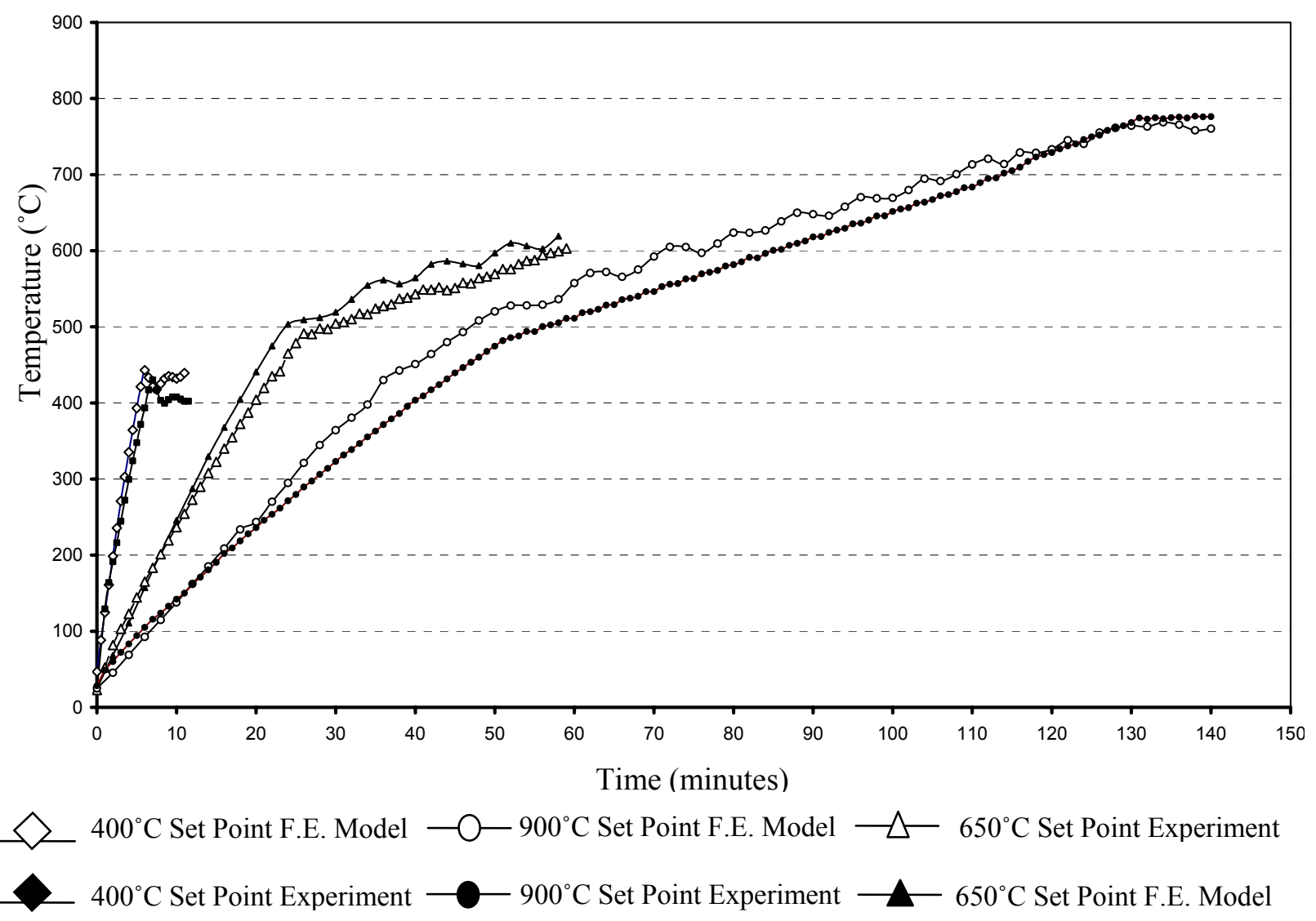

Figure 10. Comparison between Experiment and F.E. Model Results for Different Operating Conditions.

At $950^{\circ} \mathrm{C}$, the discrepancy in Figure 10 between the $900^{\circ} \mathrm{C}$ set point temperature and the temperatures measured during experiment is larger. This has not been resolved and is under investigation. The $900^{\circ} \mathrm{C}$ set point temperature experiment was performed after the heating stage had been used for over its normal lifespan. The extra use may have caused the Zircar and adhesive cement around the heating coil to break down resulting in heat leakage and potentially causing the stage's thermocouple to measure temperatures, which are not representative of the crucible (i.e. the original calibration is not valid). In addition the addition of thermocouples wires and ceramic adhesive to the crucible may cause a large temperature gradient across the heating coil. This is due to heat loss through the thermocouple wires and the additional thermal mass of the ceramic adhesive. However, there is evidence that the stage power circuit compensates for this.

\section{Demonstration of Manipulation}

The principle of manipulating a sample in the heating stage was proved using a small sample of aluminium alloy and the 1-D manipulator. Before the experiment, the 1-D manipulator probe tip was positioned on top of the sample. The probe tip applied a force on the surface such that it would indent the surface when the sample became semi-solid. The sample was heated using a heating load input used in F.E. model calibration. This heat load was demonstrated in experiment 
to provide reasonable agreement between the temperature at the crucible and the controller display temperature. At a heater controller display temperature of $650^{\circ} \mathrm{C}$, the 1-D Manipulator was activated and the probe tip moved across the sample, creating a hole in the surface. The results of the deformation are shown in Figure 11. The results clearly show the hole made by the probe tip in the sample and the deformed grains around the hole surface. The quality of the images obtained demonstrates that the presence of the probe does not degrade image quality. Further details are given in [16].

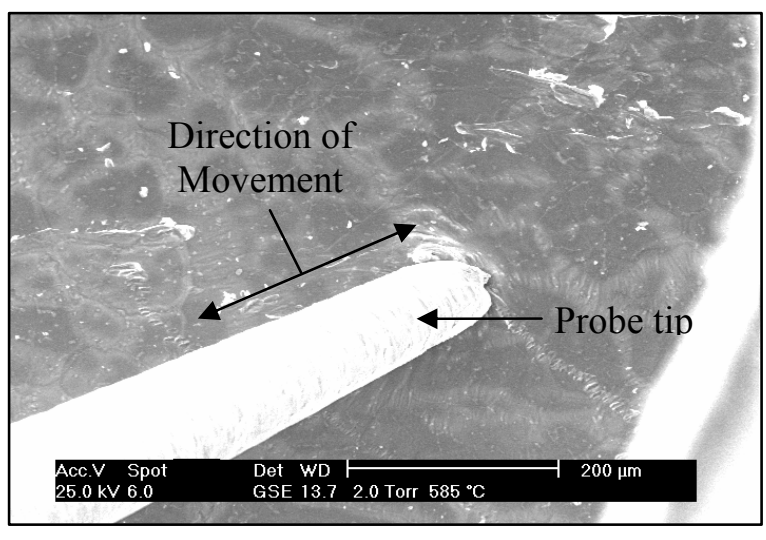

a.)

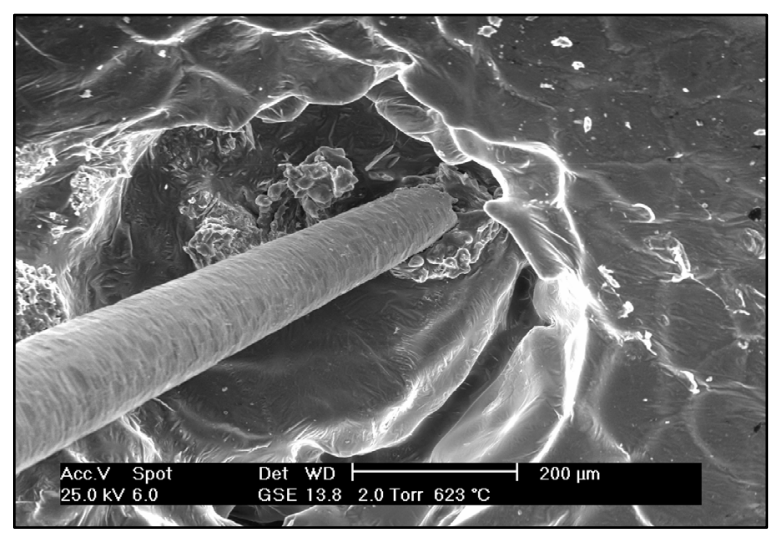

b.)

Figure 11. Demonstration of micromanipulation at a temperature of $623^{\circ} \mathrm{C}$ in an ESEM with aluminium alloy 201 (a) before probe movement (b) after probe movement. ESEM atmosphere is water vapour at 2 torr pressure.

In a second demonstration, a group of copper particles has been spread across the base of the crucible and the micromanipulator driven through at $900^{\circ} \mathrm{C}$ (Figure 12).

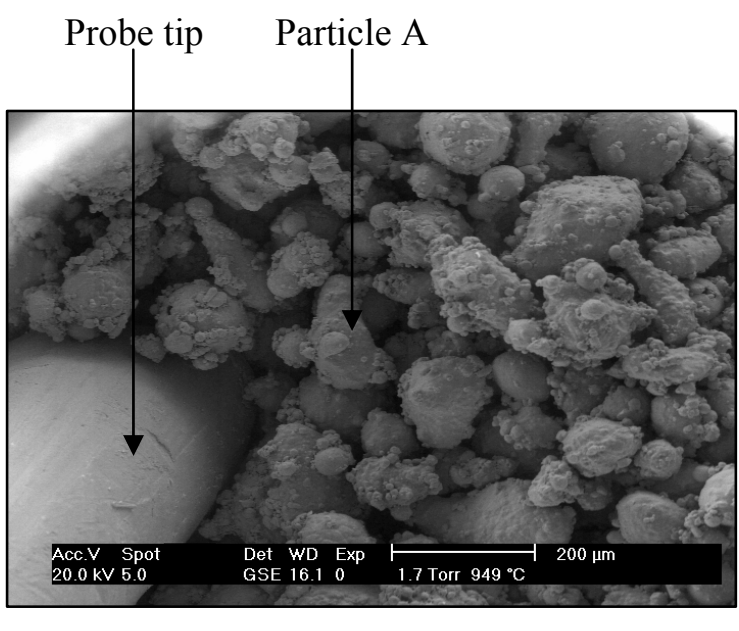

Direction of Probe Movement

a.)

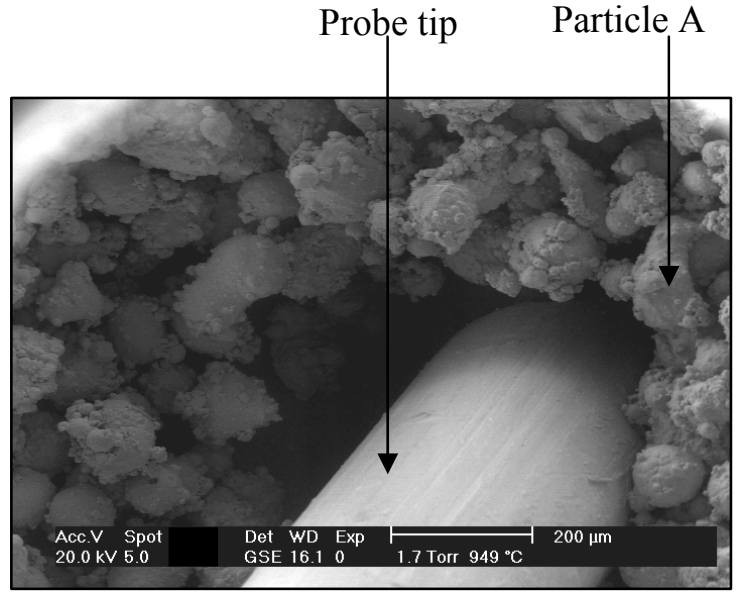

Direction of Probe Movement

b.)

Figure 12. Copper powder particles being moved by the probe tip at $949^{\circ} \mathrm{C}$ (a) before probe movement from left to right (b) after probe movement. The ESEM atmosphere is water vapour at 1.7 torr pressure. 


\section{Concluding remarks}

The aim here was to test the design of a system for high temperature micromanipulation in an Environmental Scanning Electron Microscope with finite element modelling and experimental validation. A one-dimensional probe was used as a simple, inexpensive model of a threedimensional micromanipulation system. The predictions from finite element modelling give reasonable agreement with experimental results from thermocouples although there are discrepancies the highest temperatures. These may be associated with the degradation of the insulation in the heating stage with prolonged use. The use of the one-dimensional manipulator at high temperature in the ESEM has been successfully demonstrated by making a crater in the surface of an aluminium sample and by pushing copper power particles across the base of the crucible.

\section{Acknowledgements}

The authors are grateful to Mr Andrew Smith for carrying out some of the experimental validation and to the Engineering and Physical Sciences Research Council for financial support under grant GR/S97910/01. They would like to express their thanks to Mr. Baden Flavill, Mr Tony Crawford and Mr Graham Clarke for technical support and to FEI and Mr. Ralph Knowles for technical support and cooperation.

\section{References}

[1] Danilatos G D 1988 Adv. Electron Phys. Vol. 71, p.109-250.

[2] Cocks ACF, Gill SPA, Pan J Adv Applied Mechanics 1999 Vol 36, 81.

[3] FEI Company. 5350 NE Dawson Creek Drive, Hillsboro, Oregon 97124. www.feico.com

[4] Zircar Zirconia, Inc. PO Box 287 Florida, NY 10921-0287. www.zircarzirconia.com

[5] Piezomotor Uppsala AB. Sylveniusgatan 5D, SE-754 50 Uppsala, Sweden. www.piezomotor.se/

[6] I-Deas Version 11. UGS, Norwich House Knoll Road, Camberley, Surrey GU15 3SY,United Kingdom. http://www.ugs.com/products/nx/ideas/

[7] MAYA TMG. http://www.mayahtt.com/products/thermal

[8] Harris N. 2005 Modern Vacuum Practice. Third Edition. BOC Edwards UK. Manor Royal, Crawley, RH10 9LW UK. www.modernvacuumpractice.net

[9] I-Deas 9 TMG Course Guide - Unit 14, Conductance Modelling. EDS Structural Dynamics Research Corporation. 2000 Eastman Drive, Milford, Ohio, 45150 (513)576-2400

[10] I-Deas 9 TMG Course Guide - Unit 17, Conductance Modelling. EDS Structural Dynamics Research Corporation. 2000 Eastman Drive, Milford, Ohio, 45150 (513)576-2400

[11] Kaye G.W, Laby T.H. 1995 Table of Physical and Chemical Constants. Sixteenth Edition. Longman Group Limited. Longman House, Burnt Mill, Harlow, Essex, CM20 2JE, England. ISBN 0-58222629-5

[12] Matweb - Material Properties Website. www.matweb.com

[13] I-Deas Materials Database. EDS Structural Dynamics Research Corporation. 2000 Eastman Drive, Milford, Ohio, 45150 (513)576-2400

[14] AREMCO Products Inc. PO Box 517, 707-B Executive Blvd, Valley Cottage, NY 10989. http://www.aremco.com/a2.html

[15] Yunus A, Cengel. 1998 Heat Transfer: A Practical Approach. McGraw Hill Companies Inc. ISBN 0-07-115223-7. Page 31

[16] Smith A J, Atkinson H V, Hainsworth S V, Dong HB and Haghayeghi R (2006) In Situ Environmental Scanning Electron Microscopy of Semi-Solid Samples, 9th Int Conf on Semi-Solid processing of Alloys and Composites, to be held in Busan, Korea, Sept 2006. Proceedings to be published in Solid State Phenomena. 